\title{
Sistem Pendukung Keputusan Pemilihan Lahan Untuk Tanam Bibit Pandanwangi Dengan Menggunakan Metode Moora Di Dinas Pertanian Perkebunan Pangan Dan Hortikultura Kabupaten Cianjur)
}

\author{
Selviani Kusnadi ${ }^{1,}$ Lalan Jaelani ${ }^{2}$ \\ Teknik Informatika, Universitas Suryakancana \\ selvianikusnadi01@gmail.com ${ }^{1}$,lanz8665@gmail.com²
}

\begin{abstract}
Decision Support System for Land Selection to Plant Pandanwangi Seeds Using the MOORA (Multi - Objective Optimization by Ratio Analysis) Method in the Department of Agriculture, Food Plantation and Horticulture, Cianjur Regency. This method has a level of flexibility and ease of understanding in separating the subjective part of an evaluation process into decision weight criteria with several decision-making attributes. This method also has a good level of selectivity because it can determine the objectives of conflicting criteria. Where the criteria can be beneficial (benefit) or not profitable (cost).

In making the system, the paradigm used is the waterfall model that uses UML (Unified Modeling Language) as a visualization language and design s the software to be built. Tools used in the development of Decision Support Systems are codeigniter framework for web-based systems and MySQL as a database management system.

The results of this program indicate that the Decision Support System for Land Selection for Planting Pandanwangi Seeds can be used by the Department of Agriculture, namely the food crop production sector (rice plant section) and the Sub-districts in Cianjur Regency in selecting the best land for planting Pandanwangi seeds.
\end{abstract}

Keywords: Decision Support System, Land, MOORA, Pandanwangi, Web.

\begin{abstract}
Abstrak
Sistem Pendukung Keputusan Pemilihan Lahan Untuk Tanam Bibit Pandanwangi Dengan Menggunakan Metode MOORA (Multi-Objective Optimization by Ratio Analysis) di Di Dinas Pertanian Perkebunan Pangan Dan Hortikultura Kabupaten Cianjur. Metode ini memiliki tingkat fleksibilitas dan kemudahan untuk dipahami dalam memisahkan bagian subjektif dari suatu proses evaluasi kedalam kriteria bobot keputusan dengan beberapa atribut pengambilan keputusan. Metode ini juga memiliki tingkat selektifitas yang baik karena dapat menentukan tujuan dari kriteria yang bertentangan. Dimana kriteria dapat bernilai menguntungkan (benefit) atau yang tidak menguntungkan (cost). Dalam pembuatan sistem, paradigma yang digunakan adalah waterfall model yang menggunakan UML (Unified Modelling Language) sebagai bahasa visualisasi dan merancang perangkat lunak yang akan dibangun. Tools yang digunakan dalam pembangunan Sistem Pendukung Keputusan yaitu codeigniter framework untuk sistem berbasis web dan MySQL sebagai database management system. Hasil dari program ini menunjukan bahwa Sistem Pendukung Keputusan Pemilihan Lahan untuk Tanam Bibit Pandanwangi dapat digunakan oleh pihak Dinas Pertanian yaitu bidang produksi tanaman pangan (seksi tanaman padi) beserta pihak Kecamatan yang ada di Kabupaten Cianjur dalam memilih lahan terbaik untuk tanam bibit Pandanwangi.
\end{abstract}

Kata kunci: Sistem Pendukung Keputusan, Lahan, MOORA, Pandanwangi, Web

\section{Pendahuluan}

Sistem Pendukung keputusan (SPK) adalah sistem informasi yang berbasis komputer yang fleksibel, interaktif dan dapat diadaptasi, yang dikembangkan untuk mendukung solusi untuk masalah manajemen spesifik yang tidak terstruktur. Sistem Pendukung Keputusan menggunakan data, memberikan antarmuka pengguna yang mudah dan dapat menggabungkan pemikiran pengambilan keputusan (Turban, Sharda \& Delen, 2011). Sistem Pendukung Keputusan (SPK) ini merupakan bagian dari sistem informasi berbasis komputer termasuk juga sistem berbasis pengetahuan atau manajemen pengetahuan yang dipakai untuk mendukung pengambian keputusan dalam sutu perusahaan dan dapat juga dikatakan sebagai sistem komputer yang mengolah data menjadi sebuah informasi untuk pengambilan keputusan dari suatu masalah semi terstruktur dan spesifik. Sistem Pendukung Keputusan ini bertujuan untuk menyediakan sebuah informasi, membimbing, memberikan prediksi serta mengarahkan kepada pengguna informasi agar dapat melakukan pengambilan keputusan dengan lebih tepat dan baik. Metode MOORA (Multi-Objective Optimization by Ratio Analysis) adalah metode yang diperkenalkan oleh Brauers dan Zavadkas (2006). Metode yang relatif baru ini pertama kali digunakan oleh Brauers dalam suatu 
Selviani Kusnadi ${ }^{1,}$ Lalan Jaelani ${ }^{2}$, Sistem Pendukung Keputusan Pemilihan Lahan Untuk Tanam Bibit Pandanwangi Dengan Menggunakan Metode Moora Di Dinas Pertanian Perkebunan Pangan Dan Hortikultura Kabupaten Cianjur)l

pengambilan dengan multi-kriteria. Metode MOORA memiliki tingkat fleksibilitas dan kemudahan untuk dipahami dalam memisahkan bagian subjektif dari suatu proses evaluasi kedalam kriteria bobot keputusan dengan beberapa atribut pengambilan keputusan. Metode ini memiliki tingkat selektifitas yang baik karena dapat menentukan tujuan dari kriteria yang bertentangan. Dimana kriteria dapat bernilai menguntungkan (benefit) atau yang tidak menguntungkan (cost). Metode MOORA memiliki tingkat fleksibilitas dan kemudahan untuk dipahami dalam memisahkan bagian subjektif dari suatu proses evaluasi kedalam kriteria bobot keputusan dengan beberapa atribut pengambilan keputusan (Mandal, Sarkar : 2012).

Kabupaten Cianjur merupakan kabupaten agraris dengan mata pencaharian utama dari pertanian agroindustri yang mencakup industri pengolahan hasil pertanian tanaman pangan. Komoditas tanaman pangan tertinggi di Kabupaten Cianjur adalah Padi Pandanwangi. Pandanwangi merupakan padi khas Cianjur yang berasal dari padi bulu varietas lokal yang memiliki banyak keunggulan-keunggulan. Dinas Pertanian Perkebunan Pangan dan Hortikultura merupakan unsur pelaksana urusan pemerintahan dibidang pertanian yang menjadi kewenangan dan dipimpin oleh kepala dinas yang berkedudukan di bawah dan bertanggung jawab kepada Bupati melalui Sekretaris Daerah yang mempunyai tugas membantu Bupati melaksanakan urusan pemerintahan dibidang pertanian yang menjadi kewenangan daerah.

Perkembangan penggunaan sumber daya lahan sampai saat ini belum memberikan kontribusi yang nyata dalam meningkatkan produksi tanaman pangan khususnya komoditas Padi Pandanwangi . Hal ini dipengaruhi oleh adanya alih fungsi lahan yang menyebabkan semakin berkurangnya produksi padi Pandanwangi di Kabupaten Cianjur. Alih fungsi lahan tersebut terjadi dibeberapa daerah untuk dijadikan perumahan serta industri yang masing-masing mempengaruhi produktivitas hasil Padi Pandanwangi. Dinas Pertanian Perkebunan Pangan dan Hortikultura sangat membutuhkan pengembangan untuk produktivitas Pandanwangi agar menyeluruh disetiap Kecamatan di Kabupaten Cianjur sehingga sangat dibutuhkan perencanaan yang matang dalam mengambil keputusan terutama bibit Pandanwangi yang akan ditanam. Perencanaan dan pengambilan keputusan harus dilandasi oleh data dan informasi yang akurat tentang kondisi lahan.

Meskipun telah melewati rekruitmen dan didukung surat rekomendasi dari asisten laboratorium sebelumnya. Pada faktanya beberapa praktikan masih mengeluhkan dan merasa ada beberapa asisten laboratorium yang masih tidak cukup mengampu materi praktikum, sehingga praktikan terhambat untuk menguasai materi praktikum tersebut. Selain itu ada juga yang mengeluhkan asisten praktikum yang bersikap tidak profesional seperti melanggar aturan yang telah dibuat di laboratorium sendiri dan lain - lain. Pemilihan rekomendasi calon asisten yang dilakukan dengan pemilihan berdasarkan pandangan dari asisten laboratorium itu sendiri dinilai belum cukup karena asisten tidak mengetahui seluruh kegiatan mahasiswa tersebut di Kampus. Para asisten hanya memandang keaktifan mahasiswa tersebut dipraktikum saja sedangkan diluar itu kemungkinan besar para asisten tidak mengetahuinya seperti keaktifan dikelas dan diorganisasi.

Kecamatan Cibeber Kabupaten Cianjur memiliki 18 Desa beberapa diantaranya yaitu Desa Mayak, Desa Cihaur, Desa Peuteuy Condong, Desa Cibaregbeg, Desa Sukamanah, Desa Cibadak, Desa Girimulya dengan letak geografis persawahan yang sangat luas dan masih banyak masyarakat yang bekerja sebagai petani. Seiringnya waktu produktivitas Padi Pandanwangi di Kabupaten Cianjur semakin menurun dan perlunya strategi untuk meningkatkan produktivitas Pandanwangi, oleh karena itu semua faktor yang mempengaruhi pembangunan pertanian yang berkelanjutan, baik itu faktor pendukung maupun faktor pembatas harus dipikirkan sejak awal mulai dari penentuan lahan terbaik untuk penanaman bibit Pandanwangi yang dituangkan dalam sebuah aplikasi yang dapat menjadi salah satu solusi strategi untuk meningkatkan produksi Padi Pandanwangi di beberapa Desa di Kecamatan Cibeber. Namun demikian dengan kondisi lahan yang terbatas dan kemampuan lahan tidak merata, maka pengembangan pertanian Padi khususnya Pandanwangi yang berkelanjutan harus mempertimbangkan daya dukung lingkungan. Sedangkan faktor pembatas yang sering ditemui adalah kurangnya informasi dan data yang akurat tentang kondisi sumber daya alam, dimana data dan informasi merupakan instrumen yang sangat penting dalam perencanaan pembangunan disektor pertanian Padi Pandanwangi sehingga dibutuhkan sebuah sistem pendukung keputusan yang dapat membantu dalam meningkatkan produksi Padi Pandanwangi di beberapa Desa Kecamatan Cibeber.

\section{Studi Literatur}

\section{A. Sistem Pengambilan Keputusan}

Sistem merupakan kumpulan sub-sub sistem (elemen) yang saling berkorelasi satu dengan yang lainnya untuk mencapai tujuan tertentu. Sistem Pendukung Keputusan merupakan sebuah sistem yang mampu memberikan kemampuan pemecahan masalah maupun kemampuan pengkomunikasian untuk masalah dengan kondisi semi terstruktur dan tak terstruktur. Sistem ini digunakan untuk membantu pengambilan keputusan dalam situasi semi terstruktur dan situasi yang tidak terstruktur, dimana tak seorangpun tahu secara pasti bagaimana keputusan seharusnya dibuat (Turban, 2001).

Sistem Pendukung keputusan (SPK) adalah sistem informasi yang berbasis komputer yang fleksibel, interaktif dan dapat diadaptasi, yang dikembangkan untuk mendukung solusi untuk masalah manajemen spesifik yang tidak terstruktur. Sistem Pendukung Keputusan menggunakan data, memberikan antarmuka pengguna yang mudah dan dapat menggabungkan pemikiran pengambilan keputusan (Turban, Sharda \& Delen, 2011). 


\section{b. Metode MOORA}

Metode MOORA (Multi-Objective Optimization by Ratio Analysis) adalah metode yang diperkenalkan oleh Brauers dan Zavadkas (2006). Metode yang relatif baru ini pertama kali digunakan oleh Brauers dalam suatu pengambilan dengan multi-kriteria. Metode MOORA memiliki tingkat fleksibilitas dan kemudahan untuk dipahami dalam memisahkan bagian subjektif dari suatu proses evaluasi kedalam kriteria bobot keputusan dengan beberapa atribut pengambilan keputusan. Metode ini memiliki tingkat selektifitas yang baik karena dapat menentukan tujuan dari kriteria yang bertentangan. Dimana kriteria dapat bernilai menguntungkan (benefit) atau yang tidak menguntungkan (cost).

Keunggulan MOORA yaitu sangat sederhana, stabil, dan kuat, bahkan metode ini tidak membutuhkan seorang ahli di bidang matematika untuk menggunakan nya serta membutuhkan perhitungan matematis yang sederhana. Selain itu juga metode ini juga memiliki hasil yang lebih akurat dan tepat sasaran dalam membantu pengambilan keputusan. Bila dibandingkan dengan metode yang lain metode MOORA bahkan lebih sederhana dan mudah diimplementasikan

Langkah-langkah :

1. Menentukan tujuan untuk mengidentifikasi attribut evaluasi yang bersangkutan dan menginputkan nilai kriteria pada suatu alternatif dimana nilai tersebut nantinya akan diproses dan hasilnya akan menjadi sebuah keputusan.

2. Membuat Matriks Keputusan MOORA.

$$
\boldsymbol{X}=\left[\begin{array}{ccccc}
x_{11} & \ldots & x_{1 i} & \ldots & x_{1 n} \\
\vdots & \ddots & \vdots & \ddots & \vdots \\
x_{i 1} & \ldots & x_{i j} & \ldots & x_{j n} \\
\vdots & \ddots & \ddots & \ddots & \vdots \\
x_{m 1} & \ldots & x_{m i} & \ldots & x_{m n}
\end{array}\right]
$$

3. Matriks Normalisasi Moora

Brauers, W.K., menyimpulkan bahwa untuk penyebut, pilihan terbaik adalah akar kuadrat dari jumlah kuadrat dari setiap alternatif per attribut. Rasio ini dapat dinyatakan sebagai berikut :

$$
X^{*}{ }_{i j}=\frac{x_{i j}}{\sqrt{\left[\sum_{\mathrm{j}=1}^{\mathrm{m}} x_{\mathrm{ij}}^{2}\right]}}
$$

\section{Menghitungan Nilai Pptimasi ${ }^{i} \bar{M}^{\prime}{ }^{\prime}{ }^{\prime}$ ltiobjektif MOORA. $\sum_{i=1} x_{i j} \sum_{i=g+1} x_{i j}$}

5. Menentukan Nilai Rangking dari hasil perhitungan MOORA.

Nilai yi dapat menjadi positif atau negatif tergantung dari total maksimal (attribut yang menguntungkan) dalam matriks keputusan. Sebuah urutan peringkat dari yi menunjukkan pilihan terahir. Dengan demikian alternative terbaik memiliki nilai yi tertinggi sedangkan alternatif terburuk memiliki nilai yi terendah.

\section{Metodologi Penelitian}

Metode penelitian yang digunakan yaitu waterfall. Menurut Pressman (Sumber : Pressman, 2015) model
Waterfall adalah model klasik yang bersifat sistematis, berurutan dalam membangun software. Nama model ini sebenarnya adalah "Linear Sequential Model". Model ini sering disebut juga dengan "Classic Life Cycle" atau metode Waterfall. Model ini termasuk ke dalam model generic pada rekayasa perangkat lunak dan pertama kali diperkenalkan oleh Winston Royce sekitar tahun 1970 sehingga sering dianggap kuno, tetapi merupakan model yang paling banyak dipakai dalam Software Engineering (SE). Model ini melakukan pendekatan secara sistematis dan berurutan. Disebut dengan Waterfall karena tahap demi tahap yang dilalui harus menunggu selesainya tahap sebelumnya dan berjalan berurutan. Adapun alat bantu berupa Unified Modeling Language (UML). Berikut ini adalah model proses Waterfall (Pressman, 2015) :

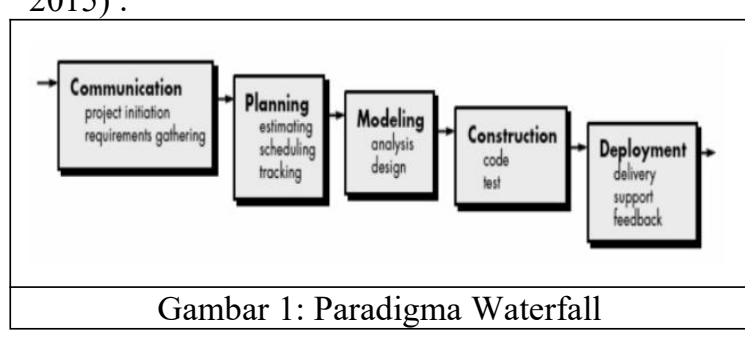

Pada Proses Pembuatan Sistem Pendukung Keputusan Pemilihan Lahan Untuk Tanam Bibit Pandanwangi Dengan Menggunakan Metode Moora Di Dinas Pertanian Perkebunan Pangan Dan Hortikultura Kabupaten Cianjur terdapat 5 Kriteria yang dapat dilihat pada

\begin{tabular}{|c|c|c|c|}
\hline Kriteria & Rating & Ket & Nilai \\
\hline \multirow{5}{*}{$\begin{array}{c}\mathrm{C} 1 . \\
\text { Ketinggian }\end{array}$} & $\begin{array}{l}\text { Sangat } \\
\text { Baik }\end{array}$ & $\begin{array}{c}900-1000 \\
\text { mdpl }\end{array}$ & 5 \\
\hline & Baik & $500-800 \mathrm{mdpl}$ & 4 \\
\hline & Cukup & $400-500 \mathrm{mdpl}$ & 3 \\
\hline & Kurang & $300-400 \mathrm{mdpl}$ & 2 \\
\hline & $\begin{array}{c}\text { Sangat } \\
\text { Kurang }\end{array}$ & 0-200 mdpl & 1 \\
\hline \multirow{5}{*}{$\begin{array}{l}\text { C2. Curah } \\
\text { Hujan }\end{array}$} & $\begin{array}{l}\text { Sangat } \\
\text { Baik }\end{array}$ & $\begin{array}{c}3000-4000 \\
\mathrm{~mm} / \mathrm{thn}\end{array}$ & 5 \\
\hline & Baik & $\begin{array}{c}2000-3000 \\
\mathrm{~mm} / \mathrm{thn}\end{array}$ & 4 \\
\hline & Cukup & $\begin{array}{c}1000- \\
2000 \mathrm{~mm} / \mathrm{thn}\end{array}$ & 3 \\
\hline & Kurang & $\begin{array}{c}800-1000 \\
\mathrm{~mm} / \mathrm{thn}\end{array}$ & 2 \\
\hline & $\begin{array}{l}\text { Sangat } \\
\text { Kurang }\end{array}$ & $0-800 \mathrm{~mm} / \mathrm{thn}$ & 1 \\
\hline \multirow{5}{*}{$\begin{array}{c}\text { C3. } \\
\text { Suhu Udara }\end{array}$} & $\begin{array}{l}\text { Sangat } \\
\text { Baik }\end{array}$ & $25-29 \circ \mathrm{C}$ & 5 \\
\hline & Baik & $20-25^{\circ} \mathrm{C}$ & 4 \\
\hline & Cukup & $15-20^{\circ} \mathrm{C}$ & 3 \\
\hline & Kurang & $10-15^{\circ} \mathrm{C}$ & 2 \\
\hline & $\begin{array}{l}\text { Sangat } \\
\text { Kurang }\end{array}$ & $<15^{\circ} \mathrm{C}$ & 1 \\
\hline $\begin{array}{c}\text { C4. } \\
\text { pH Tanah }\end{array}$ & $\begin{array}{c}\text { Sangat } \\
\text { Baik }\end{array}$ & $7-10$ & 5 \\
\hline
\end{tabular}

Tabel 15 Kriteria Lahan 
Selviani Kusnadi ${ }^{1,}$ Lalan Jaelani ${ }^{2}$, Sistem Pendukung Keputusan Pemilihan Lahan Untuk Tanam Bibit Pandanwangi Dengan Menggunakan Metode Moora Di Dinas Pertanian Perkebunan Pangan Dan Hortikultura Kabupaten Cianjur)1

\begin{tabular}{|c|c|c|c|}
\hline Kriteria & $\overline{\text { Rating }}$ & Ket & Nilai \\
\hline & Baik & $5,5-7$ & 4 \\
\hline & Cukup & $4,5-5,5$ & 3 \\
\hline & Kurang & $1-2$ & 2 \\
\hline & $\begin{array}{c}\text { Sangat } \\
\text { Kurang }\end{array}$ & $0-1$ & 1 \\
\hline \multirow{5}{*}{$\begin{array}{c}\text { C5. } \\
\text { Tekstur } \\
\text { Tanah }\end{array}$} & $\begin{array}{c}\text { Sangat } \\
\text { Baik }\end{array}$ & Tanah Liat & 5 \\
\hline & Baik & $\begin{array}{c}\text { Tanah } \\
\text { Lempung Liat }\end{array}$ & 4 \\
\hline & Cukup & $\begin{array}{c}\text { Tanah } \\
\text { Lempung } \\
\text { Berpasir }\end{array}$ & 3 \\
\hline & Kurang & $\begin{array}{c}\text { Tanah Liat } \\
\text { Berdebu }\end{array}$ & 2 \\
\hline & $\begin{array}{c}\text { Sangat } \\
\text { Kurang }\end{array}$ & $\begin{array}{c}\text { Tanah Pasir } \\
\text { Berdebu }\end{array}$ & 1 \\
\hline
\end{tabular}

Dari masing-masing kriteria tersebut diberi bobot dengan menggunakan interval 1-100 untuk masingmasing kriteria dengan prioritas tertinggi. Pemberian bobot dari setiap kriteria dapat dilihat pada tabel 2 :

Tabel 2 Bobot Kriteria

\begin{tabular}{|c|c|c|c|}
\hline $\begin{array}{c}\text { Kode } \\
\text { Kriteria }\end{array}$ & Kriteria & Bobot & Jenis \\
\hline C1 & Ketinggian & 0,30 & Benefit \\
\hline C2 & Curah Hujan & 0,20 & Benefit \\
\hline C3 & Suhu Udara & 0,20 & Benefit \\
\hline C4 & pH Tanah & 0,15 & Benefit \\
\hline C5 & $\begin{array}{c}\text { Tekstur } \\
\text { Tanah }\end{array}$ & 0,15 & Benefit \\
\hline
\end{tabular}

Dalam metode MOORA (Multi-Objective Optimization by Ratio Analysis) dalam pemilihan lahan untuk tanam bibit Pandanwangi diperlukan kriteriakriteria dan bobot untuk melakukan perhitungannya agar didapatkan alternatif terbaik. Berikut contoh kasus berdasarkan tabel 3 :

\begin{tabular}{|c|c|c|c|c|c|}
\hline \multirow{2}{*}{ Alt } & \multicolumn{5}{|c|}{ Kriteria } \\
\hline & C1 & $\mathrm{C} 2$ & C3 & C4 & C5 \\
\hline A1 & $\begin{array}{c}500- \\
900 \\
\text { Mdpl }\end{array}$ & $\begin{array}{c}2000- \\
2500 \\
\mathrm{Mm} / \mathrm{Thn}\end{array}$ & $22{ }^{\circ} \mathrm{C}$ & 7.12 & $\begin{array}{c}\text { Tanah } \\
\text { Liat }\end{array}$ \\
\hline $\mathrm{A} 2$ & $\begin{array}{l}500- \\
1035 \\
\text { Mdpl }\end{array}$ & $\begin{array}{c}2000- \\
3000 \\
\text { Mm/Thn }\end{array}$ & $24 \circ \mathrm{C}$ & 6.48 & $\begin{array}{c}\text { Tanah } \\
\text { Liat }\end{array}$ \\
\hline A3 & $\begin{array}{c}436- \\
675 \\
\text { Mdpl }\end{array}$ & $\begin{array}{c}2000- \\
2500 \\
\mathrm{Mm} / \mathrm{Thn}\end{array}$ & $20 \circ \mathrm{C}$ & 7.12 & $\begin{array}{c}\text { Tanah } \\
\text { Liat }\end{array}$ \\
\hline A4 & $\begin{array}{l}300- \\
1250 \\
\text { Mdpl }\end{array}$ & $\begin{array}{c}1500- \\
2000 \\
\mathrm{Mm} / \mathrm{Thn}\end{array}$ & $21{ }^{\circ} \mathrm{C}$ & 6.48 & $\begin{array}{c}\text { Tanah } \\
\text { Liat }\end{array}$ \\
\hline A5 & $\begin{array}{c}436- \\
675 \\
\text { Mdpl }\end{array}$ & $\begin{array}{c}2000- \\
2500 \\
\mathrm{Mm} / \mathrm{Thn}\end{array}$ & $21{ }^{\circ} \mathrm{C}$ & 7.0 & $\begin{array}{c}\text { Tanah } \\
\text { Liat }\end{array}$ \\
\hline
\end{tabular}

\begin{tabular}{|c|c|c|c|c|c|}
\hline A6 & $\begin{array}{c}500- \\
900 \\
\text { Mdpl }\end{array}$ & $\begin{array}{c}<1000 \\
\mathrm{Mm} / \mathrm{Thn}\end{array}$ & $20^{\circ} \mathrm{C}$ & 6,09 & $\begin{array}{c}\text { Tanah } \\
\text { Liat }\end{array}$ \\
\hline A7 & $\begin{array}{c}470- \\
700 \\
\text { Mdpl }\end{array}$ & $\begin{array}{c}1000- \\
1500 \\
\mathrm{Mm} / \mathrm{Thn}\end{array}$ & $21^{\circ} \mathrm{C}$ & 6.48 & $\begin{array}{c}\text { Tanah } \\
\text { Liat }\end{array}$ \\
\hline
\end{tabular}

Hasil dari contoh kasus yang dapat dilihat pada tabel 4, dikonversikan ke dalam logika Moora dengan cara mencocokan dengan rating yang sudah ditentukan. Hasil konversi dapat dilihat pada table 4 :

Tabel 4 Matriks Keputusan MOORA

\begin{tabular}{|c|c|c|c|c|c|}
\hline \multirow{2}{*}{ Alt } & \multicolumn{5}{|c|}{ Kriteria } \\
\cline { 2 - 6 } & C1 & C2 & C3 & C4 & C5 \\
\hline A1 & 5 & 4 & 4 & 5 & 5 \\
\hline A2 & 5 & 4 & 4 & 4 & 5 \\
\hline A3 & 4 & 4 & 4 & 5 & 5 \\
\hline A4 & 5 & 3 & 4 & 4 & 5 \\
\hline A5 & 4 & 4 & 4 & 4 & 5 \\
\hline A6 & 5 & 2 & 4 & 4 & 5 \\
\hline A7 & 4 & 3 & 4 & 4 & 5 \\
\hline
\end{tabular}

1. Pembuatan Matriks Keputusan MOORA

Tabel 5 Matriks Keputusan MOORA

\begin{tabular}{|l|l|l|l|l|}
\hline 5 & 4 & 4 & 5 & 5 \\
\hline 5 & 4 & 4 & 4 & 5 \\
\hline 4 & 4 & 4 & 5 & 5 \\
\hline 5 & 3 & 4 & 4 & 5 \\
\hline 4 & 4 & 4 & 4 & 5 \\
\hline 5 & 2 & 4 & 4 & 5 \\
\hline 4 & 3 & 4 & 4 & 5 \\
\hline
\end{tabular}

2. Melakukan Normalisasi dengan Metode Moora Perhitungan :

$$
\begin{aligned}
\mathrm{C} 1 & =\sqrt{ } 5^{2}+5^{2}+4^{2}+5^{2}+4^{2}+5^{2}+4^{2} \\
& =\sqrt{ } 25+25+16+25+16+25+16 \\
& =12.1655 \\
\mathrm{~A} 11 & =5 / 12.1655 \\
& =0.4109 \\
\mathrm{~A} 21 & =5 / 12.1655 \\
& =0.4109 \\
\mathrm{~A} 31 & =4 / 12.1655 \\
& =0.3287 \\
\mathrm{~A} 41 & =5 / 12.1655 \\
& =0.4109 \\
\mathrm{~A} 51 & =4 / 12.1655
\end{aligned}
$$




\begin{tabular}{|c|c|c|c|c|c|c|}
\hline & $=0.3287$ & \multicolumn{5}{|c|}{$\mathrm{A} 14=5 / 11.4017$} \\
\hline A61 & $=5 / 12.1655$ & \multicolumn{5}{|c|}{$=0.4385$} \\
\hline & $=0.4109$ & \multicolumn{5}{|c|}{$\mathrm{A} 24=4 / 11.4017$} \\
\hline A71 & $=4 / 12.1655$ & \multicolumn{5}{|c|}{$=0.3508$} \\
\hline & $=0.3287$ & \multicolumn{5}{|c|}{$\mathrm{A} 34=5 / 11.4017$} \\
\hline \multirow[t]{3}{*}{$\mathrm{C} 2$} & $=\sqrt{ } 4^{2}+4^{2}+4^{2}+3^{2}+4^{2}+2^{2}+3^{2}$ & \multicolumn{5}{|c|}{$=0.4385$} \\
\hline & $=\sqrt{ } 16+16+16+9+16+4+9$ & \multicolumn{5}{|c|}{$\mathrm{A} 44=4 / 11.4017$} \\
\hline & $=9.2736$ & \multicolumn{5}{|c|}{$=0.3508$} \\
\hline A12 & $=4 / 9.2736$ & \multicolumn{5}{|c|}{$\mathrm{A} 54=4 / 11.4017$} \\
\hline & $=0.4313$ & \multicolumn{5}{|c|}{$=0.3508$} \\
\hline A22 & $=4 / 9.2736$ & \multicolumn{5}{|c|}{$\mathrm{A} 64=4 / 11.4017$} \\
\hline & $=0.4313$ & \multicolumn{5}{|c|}{$=0.3508$} \\
\hline A 32 & $=4 / 9.2736$ & \multicolumn{5}{|c|}{$\mathrm{A} 74=4 / 11.4017$} \\
\hline & $=0.4313$ & \multicolumn{5}{|c|}{$=0.3508$} \\
\hline $\mathrm{A} 42$ & $=3 / 9.2736$ & \multirow{2}{*}{$\begin{aligned} \mathrm{C} 5 & = \\
& =\end{aligned}$} & \multicolumn{4}{|c|}{$=\sqrt{ } 5^{2}+5^{2}+5^{2}+5^{2}+5^{2}+5^{2}+5^{2}$} \\
\hline & $=0.3234$ & & \multicolumn{4}{|c|}{$=\sqrt{ } 25+25+25+25+25+25+25$} \\
\hline A52 & $=4 / 9.2736$ & \multicolumn{5}{|c|}{$=13.2287$} \\
\hline & $=0.4313$ & \multicolumn{5}{|c|}{$\mathrm{A} 15=5 / 13.2287$} \\
\hline A62 & $=2 / 9.2736$ & \multicolumn{5}{|c|}{$=0.3779$} \\
\hline & $=0.2156$ & \multicolumn{5}{|c|}{$\mathrm{A} 25=5 / 13.2287$} \\
\hline A72 & $=3 / 9.2736$ & \multicolumn{5}{|c|}{$=0.3779$} \\
\hline & $=0.3234$ & \multicolumn{5}{|c|}{$\mathrm{A} 35=5 / 13.2287$} \\
\hline $\mathrm{C} 3$ & $=\sqrt{ } 4^{2}+4^{2}+4^{2}+4^{2}+4^{2}+4^{2}+4^{2}$ & \multicolumn{5}{|c|}{$=0.3779$} \\
\hline & $=\sqrt{ } 16+16+16+16+16+16+16$ & $\mathrm{~A} 45=5$ & /13.2287 & & & \\
\hline & $=10.5830$ & $=0$ & .3779 & & & \\
\hline A 13 & $=4 /=10.5830$ & $\mathrm{~A} 55=5$ & /13.2287 & & & \\
\hline & $=0.3779$ & $=0$ & .3779 & & & \\
\hline $\mathrm{A} 23$ & $=4 /=10.5830$ & $\mathrm{~A} 65=5$ & /13.2287 & & & \\
\hline & $=0.3779$ & $=0$ & .3779 & & & \\
\hline A33 & $=4 /=10.5830$ & $\mathrm{~A} 75=5$ & /13.2287 & & & \\
\hline & $=0.3779$ & $=0$ & .3779 & & & \\
\hline $\mathrm{A} 43$ & $=4 /=10.5830$ & Maka dapat & dilihat $n$ & atriks tern & ormalisasi & berikut pada \\
\hline & $=0.3779$ & tabel 3.6 & & & & \\
\hline A53 & $=4 /=10.5830$ & & Tabel 6 & Matriks N & rmalisasi & \\
\hline & $=0.3779$ & 0.4109 & 0.4313 & 0.3779 & 0.4385 & 0.3779 \\
\hline A63 & $=4 /=10.5830$ & 0.4109 & 0.4313 & 0.3779 & 0.3508 & 0.3779 \\
\hline & $=0.000037$ & 0.3287 & 0.4313 & 0.3779 & 0.4385 & 0.3779 \\
\hline A73 & $=4 /=10.5830$ & 0.4109 & 0.3234 & 0.3779 & 0.3508 & 0.3779 \\
\hline & $=0.3779$ & 0.3287 & 0.4313 & 0.3779 & 0.3508 & 0.3779 \\
\hline $\mathrm{C} 4$ & $=\sqrt{ } 5^{2}+4^{2}+5^{2}+4^{2}+4^{2}+4^{2}+4^{2}$ & 0.4109 & 0.2156 & 0.3779 & 0.3508 & 0.3779 \\
\hline & $=\sqrt{ } 25+16+25+16+16+16+16$ & 0.3287 & 0.3234 & 0.3779 & 0.3508 & 0.3779 \\
\hline
\end{tabular}


Selviani Kusnadi ${ }^{1,}$ Lalan Jaelani ${ }^{2}$, Sistem Pendukung Keputusan Pemilihan Lahan Untuk Tanam Bibit Pandanwangi Dengan Menggunakan Metode Moora Di Dinas Pertanian Perkebunan Pangan Dan Hortikultura Kabupaten Cianjur)l

\begin{tabular}{|c|c|c|c|c|c|c|}
\hline \multirow{2}{*}{\multicolumn{2}{|c|}{$\begin{array}{l}\text { 3. Matriks Ternormalisasi Terbobot } \\
\text { Perhitungan : }\end{array}$}} & 0.1232 & 0.0862 & 0.0755 & 0.1657 & 0.0566 \\
\hline & & 0.1232 & 0.0862 & 0.0755 & 0.0526 & 0.0566 \\
\hline \multirow{5}{*}{$\mathrm{C} 1$} & \multirow{2}{*}{$=\mathrm{A}_{11}: 0.30 \times 0.4109=0.1232$} & 0.0986 & 0.0862 & 0.0755 & 0.1657 & 0.0566 \\
\hline & & 0.1232 & 0.0646 & 0.0755 & 0.0526 & 0.0566 \\
\hline & \multirow{3}{*}{$\begin{array}{l}\mathrm{A}_{21}: 0.30 \times 0.4109=0.1232 \\
\mathrm{~A}_{31}: 0.30 \times 0.3287=0.0986\end{array}$} & 0.0986 & 0.0862 & 0.0755 & 0.0526 & 0.0566 \\
\hline & & 0.1232 & 0.0431 & 0.0755 & 0.0526 & 0.0566 \\
\hline & & 0.0986 & 0.0646 & 0.0755 & 0.0526 & 0.0566 \\
\hline
\end{tabular}

$\mathrm{A}_{41}: 0.30 \times 0.4109=0.1232$

$\mathrm{A}_{51}: 0.30 \times 0.3287=0.0986$

$\mathrm{A}_{61}: 0.30 \times 0.4109=0.1232$

$\mathrm{A}_{71}: 0.30 \times 0.3287=0.0986$

$\mathrm{C} 2=\mathrm{A}_{12}: 0.20 \times 0.4313=0.0862$

$\mathrm{A}_{22}: 0.20 \times 0.4313=0.0862$

$\mathrm{A}_{32}: 0.20 \times 0.4313=0.0862$

$\mathrm{A}_{42}: 0.20 \times 0.3234=0.0646$

$\mathrm{A}_{52}: 0.20 \times 0.4313=0.0862$

$\mathrm{A}_{62}: 0.20 \times 0.2156=0.0431$

$\mathrm{A}_{72}: 0.20 \times 0.3234=0.0646$

$=\mathrm{A}_{13}: 0.20 \times 0.3779=0.0755$

$\mathrm{A}_{23}: 0.20 \times 0.3779=0.0755$

$\mathrm{A}_{33}: 0.20 \times 0.3779=0.0755$

$\mathrm{A}_{43}: 0.20 \times 0.3779=0.0755$

$\mathrm{A}_{53}: 0.20 \times 0.3779=0.0755$

$\mathrm{A}_{63}: 0.20 \times 0.3779=0.0755$

$\mathrm{A}_{73}: 0.20 \times 0.3779=0.0755$

$=\mathrm{A}_{14}: 0.15 \times 0.4385=0.1657$

$\mathrm{A}_{24}: 0.15 \times 0.3508=0.0526$

$\mathrm{A}_{34}: 0.15 \times 0.4385=0.1657$

$\mathrm{A}_{44}: 0.15 \times 0.3508=0.0526$

$\mathrm{A}_{54}: 0.15 \times 0.3508=0.0526$

$\mathrm{A}_{64}: 0.15 \times 0.3508=0.0526$

$\mathrm{A}_{74}: 0.15 \times 0.3508=0.0526$

$\mathrm{A}_{25}: 0.15 \times 0.3779=0.0566$

$\mathrm{A}_{35}: 0.15 \times 0.3779=0.0566$

$\mathrm{A}_{45}: 0.15 \times 0.3779=0.0566$

$\mathrm{A}_{55}: 0.15 \times 0.3779=0.0566$

$\mathrm{A}_{65}: 0.15 \times 0.3779=0.0566$

$\mathrm{A}_{75}: 0.15 \times 0.3779=0.0566$

Maka dapat dilihat Hasil Matriks Ternormalisasi Terbobot berikut pada tabel 7 :

Tabel 7 Hasi Matriks Ternormalisasi

4. Pencarian Nilai $Y i$

Tabel 8 Nilai Yi

\begin{tabular}{|c|c|c|c|}
\hline Alt & $\begin{array}{c}\text { Max } \\
(\mathrm{C} 1+\mathrm{C} 2+\mathrm{C} 3+\mathrm{C} 4+\mathrm{C} 5)\end{array}$ & $\begin{array}{c}\text { Mi } \\
\text { n } \\
(0)\end{array}$ & $\begin{array}{c}\text { Yi }= \\
\text { Max - } \\
\text { Min }\end{array}$ \\
\hline $\mathrm{A} 1$ & $\begin{array}{l}(0.1232+0.0862+0.0755 \\
+0.0657+ \\
0.0566)\end{array}$ & 0 & 0.4076 \\
\hline A2 & $\begin{array}{l}(0.1232+0.0862+0.0755 \\
+0.0526+ \\
0.0566)\end{array}$ & 0 & 0.3944 \\
\hline A3 & $\begin{array}{l}(0.0986+0.0862+0.0755 \\
+0.1657+ \\
0.0566)\end{array}$ & 0 & 0.3828 \\
\hline A4 & $\begin{array}{l}(0.1232+0.0646+0.0755 \\
+0.0526+ \\
0.0566) \\
\end{array}$ & 0 & 0.3729 \\
\hline A5 & $\begin{array}{l}(0.0986+0.0862+0.0755 \\
+0.0526+ \\
0.0566)\end{array}$ & 0 & 0.3698 \\
\hline A6 & $\begin{array}{l}(0.1232+0.0431+0.0755 \\
+0.0526+ \\
0.0566)\end{array}$ & 0 & 0.3513 \\
\hline A7 & $\begin{array}{l}(0.0986+0.0646+0.0755 \\
+0.0526+ \\
0.0566)\end{array}$ & 0 & 0.3482 \\
\hline
\end{tabular}

Adapun Hasi Perengkingan Sebagai Berikut :

Tabel 9 Hasil Perengkingan

\begin{tabular}{|c|c|c|}
\hline Alternatif & $\boldsymbol{Y i}$ & Rangking \\
\hline $\mathrm{A} 1$ & 0.4076 & 1 \\
\hline $\mathrm{A} 2$ & 0.3944 & 2 \\
\hline $\mathrm{A} 3$ & 0.3829 & 3 \\
\hline $\mathrm{A} 4$ & 0.3729 & 4 \\
\hline $\mathrm{A} 5$ & 0.3698 & 5 \\
\hline $\mathrm{A} 6$ & 0.3513 & 6 \\
\hline $\mathrm{A} 7$ & 0.3482 & 7 \\
\hline
\end{tabular}

Setelah dicocokan dengan rating pemilihan lahan. Maka, dapat disimpulkan bahwa alternatif 1 yaitu Desa Mayak Kecamatan Cibeber sebagai rekomendasi lahan yang terbaik dengan hasil nilai 0.4076 .

\subsection{Use Case Diagram}

Use Case Diagram mendeskripsikan kelakuan sistem dari sudut pandang pengguna, berguna untuk membantu memahami kebutuhan. Use case adalah dasar dari diagram lain. Use case adalah abstraksi dari interaksi antara system dan actor. Use case berkerja dengan mendeskripsikan tipe interaksi antara actor sebuah system dengan sistemnya sendiri melalui sebuah 
cerita bagaimana sebuah system dipakai. Berikut merupakan Use Case Diagram dari Sistem Pendukung Keputusan Pemilihan Lahan Untuk Tanam Bibit Pandanwangi Dengan Menggunakan Metode Moora Di Dinas Pertanian Perkebunan Pangan Dan Hortikultura Kabupaten Cianjur. Use case diagram dapat dilihat pada Gambar 3 berikut ini:

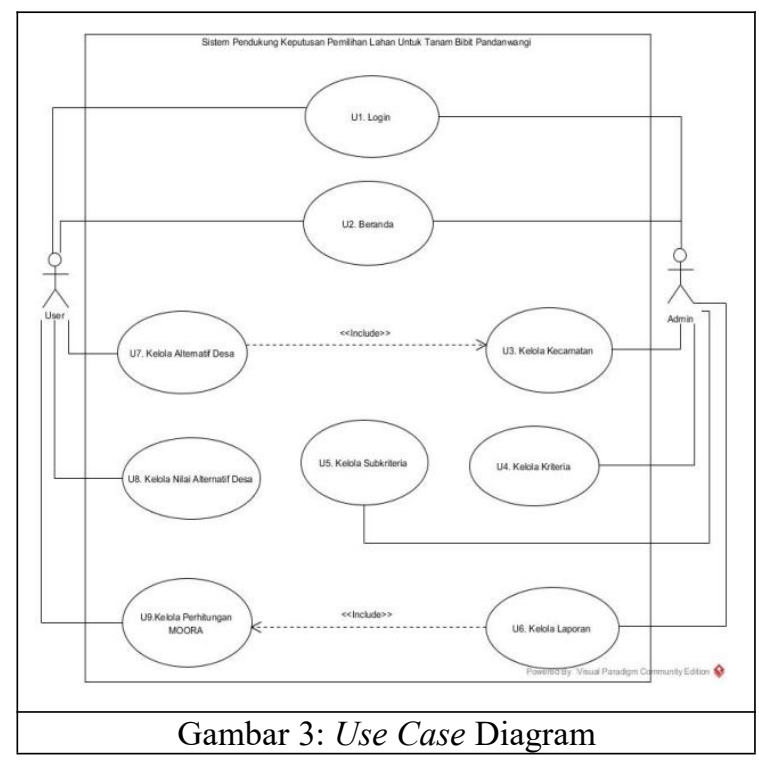

\subsection{Swimlane Diagram Kelola Perhitungan MOORA}

Kelola Perhitungan MOORA menunjukan aktivitas user dalam melihat proses perhitungan pemilihan lahan untuk tanam bibit Pandanwangi. Diawali dengan klik menu Perhitungan MOORA, lalu sistem akan menampilkan halaman Normalisasi Perhitungan MOORA. Di halaman tersebut user klik tombol Lanjut Normalisasi Terbobot dan sistem menampilkan halaman Normalisasi terbobot. Di halaman tersebut user klik tombol Lanjut Hasil Akhir. Sistem menampilkan hasil akhir Perhitungan MOORA pada Gambar 4 :

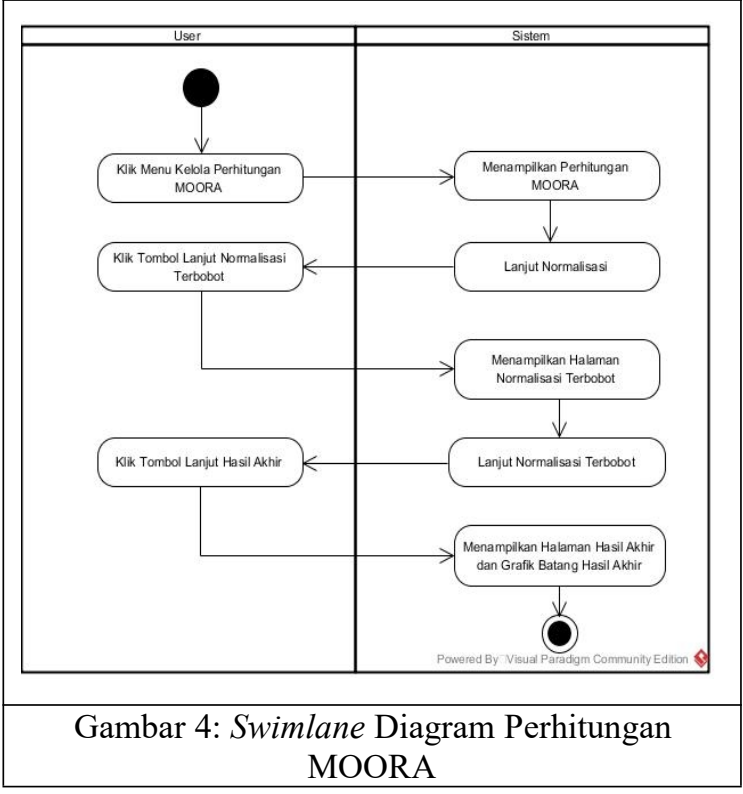

\subsection{Class Diagram}

Class Diagram adalah pandangan aplikasi yang statis. Class Diagram tidak hanya menggambarkan visualisasi, menggambarkan dan mendokumentasikan aspek yang berbeda dalam sistem, tetapi juga untuk kontruksi eksekusi kode dalam software aplikasi. Class Diagram digunakan untuk mengelompokkan hal-hal inti dari setiap proses yang ingin dilakukan. Semua proses dimasukkan ke dalam tiap-tiap Class dan saling dihubungkan pada Class-Class lainnya yang saling berhubungan, Berikut merupakan Class Diagram dari Sistem Pendukung Keputusan Pemilihan Lahan Untuk Tanam Bibit Pandanwangi Dengan Menggunakan Metode Moora Di Dinas Pertanian Perkebunan Pangan Dan Hortikultura Kabupaten Cianjur pada Gambar 5 :

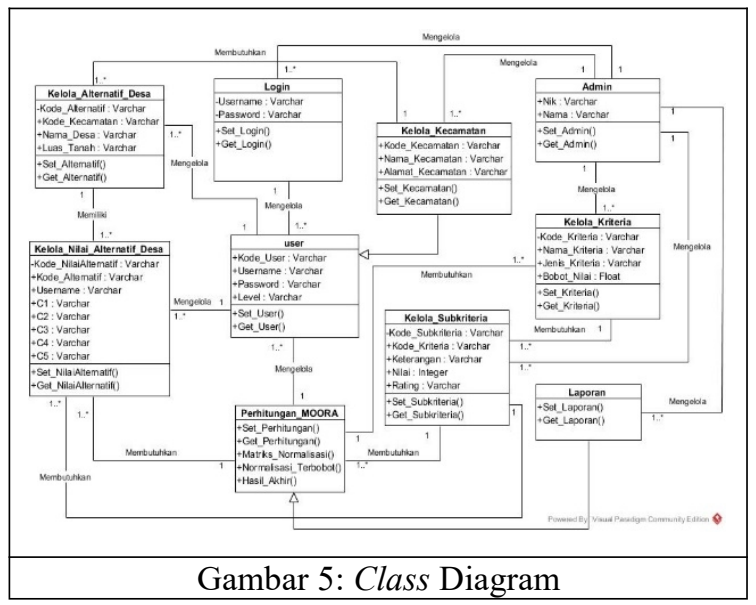

\subsection{Sequence Diagram Kelola Perhitungan MOORA}

Berikut ini merupakan sequence diagram dari proses perhitungan MOORA pada Sistem Pendukung Keputusan Pemilihan Lahan Untuk Tanam Bibit Pandanwangi Dengan Menggunakan Metode Moora Di Dinas Pertanian Perkebunan Pangan Dan Hortikultura Kabupaten Cianjur.

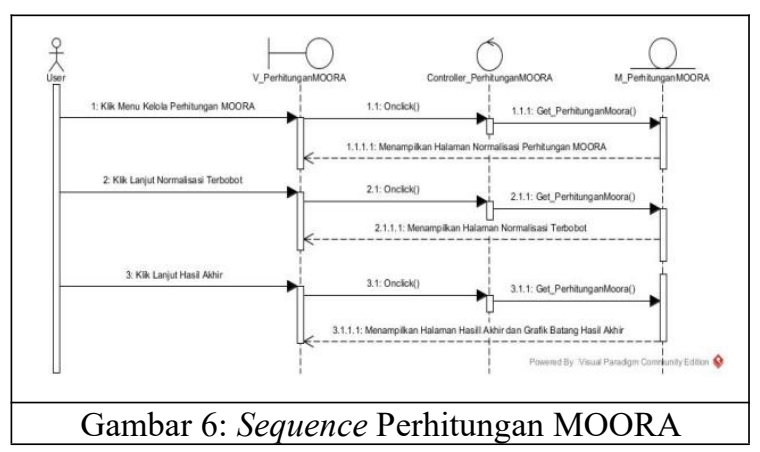

\section{$3.5 \mathrm{ERD}$}

Entity Relationship Diagram adalah suatu model yang digunakan untuk menggambarkan data dalam bentuk entitas (entity), atribut dan hubungan antar entitas (relationship). Suatu entity bersifat unik dan memiliki atribut sebagai pembeda dengan entity lainnya. Berikut merupakan Entity Relationship Diagram dari Sistem Pendukung Keputusan Pemilihan Lahan Untuk Tanam Bibit Pandanwangi Dengan Menggunakan Metode 
Selviani Kusnadi ${ }^{1}$, Lalan Jaelani ${ }^{2}$, Sistem Pendukung Keputusan Pemilihan Lahan Untuk Tanam Bibit Pandanwangi Dengan Menggunakan Metode Moora Di Dinas Pertanian Perkebunan Pangan Dan Hortikultura Kabupaten Cianjur)1

Moora Di Dinas Pertanian Perkebunan Pangan Dan Hortikultura Kabupaten Cianjur pada Gambar 7:

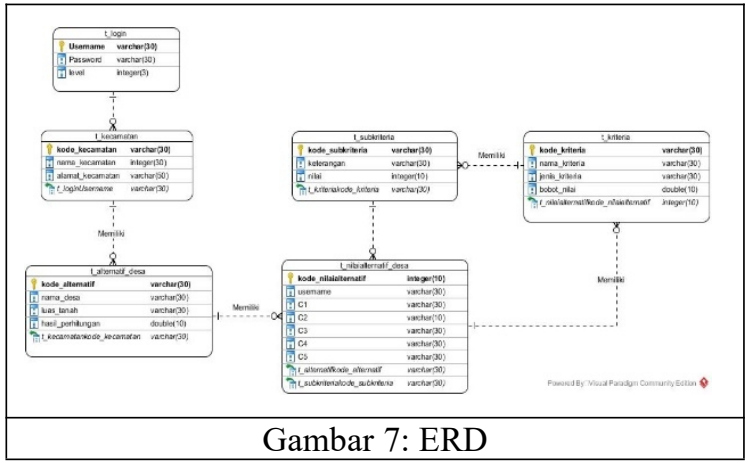

\section{Implementasi}

Tahap implementasi dapat diterapkan jika sistem perangkat lunak dan perangkat kerasnya telah dipersiapkan. Kegiatan implementasi sistem ini meliputi kebutuhan perangkat lunak, perangkat keras, instalasi aplikasi dan implementasi antarmuka, serta pengujian aplikasi sistem yang telah dirancang sesuai dengan kebutuhan organisasi.
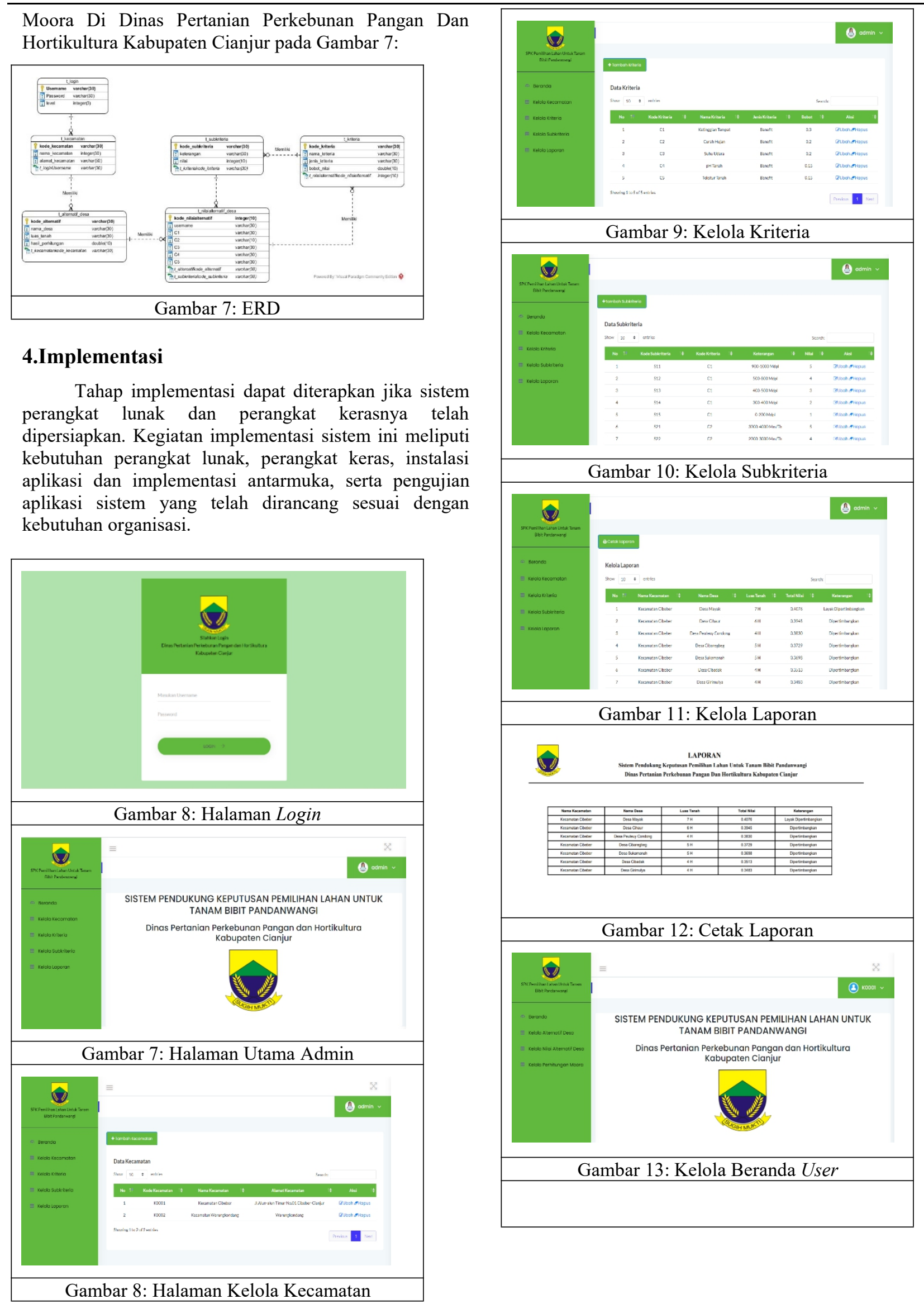


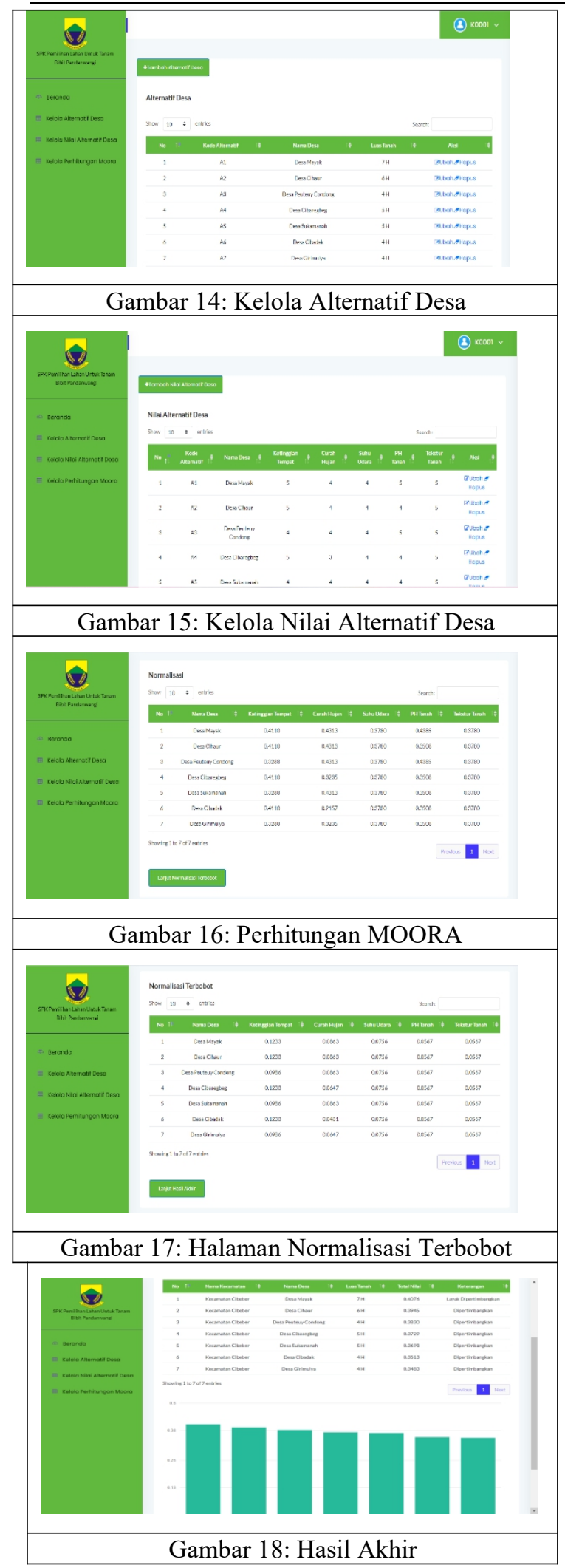

\section{Kesimpulan}

Berdasarkan hasil analisis, perancangan dan implementasi selama melaksanakan penelitian Tugas Akhir yang berjudul Sistem Pendukung Keputusan Pemilihan Lahan Untuk Tanam Bibit Pandanwangi Dengan Menggunakan Metode Moora Di Dinas
Pertanian Perkebunan Pangan Dan Hortikultura Kabupaten Cianjur dapat disimpulkan bahwa :

1. Telah dibangun Sistem Pendukung Keputusan Pemilihan Lahan yang dapat membantu memudahkan Dinas Pertanian Perkebunan Pangan dan Hortikultura Kabupaten Cianjur agar lebih tepat dan efektif dalam memilih lahan untuk tanam bibit Pandanwangi.

2. Telah dibangun Sistem Pendukung Keputusan Pemilihan Lahan yang dapat membantu memudahkan Seksi Produksi Tanaman Padi dalam merekap laporan pemilihan lahan untuk tanam bibit Pandanwangi dengan akurat.

3. Telah dibangun Sistem Pendukung Keputusan Pemilihan Lahan yang dapat memberikan kemudahan kepada pihak Kecamatan agar dapat menentukan pemilihan lahan terbaik untuk tanam bibit Pandanwangi.

\section{A. Saran}

Untuk meningkatkan kinerja Sistem Pendukung Keputusan Pemilihan Lahan Untuk Tanam Bibit Pandanwangi di Dinas Pertanian Perkebunan Pangan Dan Hortikultura Kabupaten Cianjur, maka penulis menyarankan beberapa hal yaitu :

1. Diperlukannya pengguna yang dapat menguasai komputer dan mengerti cara menggunakan sebuah Sistem Pendukung Keputusan Pemilihan Lahan Untuk Tanam Bibit Pandanwangi dengan terlebih dahulu diberikan pelatihan. Hal ini diharapkan agar proses pengelolaan data dapat berjalan dengan maksimal dan untuk mengurangi human error.

2. Sistem yang terkomputerisasi senantiasa tetap harus dipelihara secara rutin untuk menjaga keamanan data.

3. Perlu disajikan dalam GIS (Geographic Information System) agar lebih menarik.

\section{Daftar Pustaka}

[1.] Adila, W. N., Regasari, R., \& Nurwasito, H. (2018). Sistem Pendukung Keputusan (SPK) Pemilihan Tanaman Pangan Pada Suatu Lahan Berdasarkan Kondisi Tanah Dengan Metode Promethee. Jurnal Pengembangan Teknologi Informasi Dan Ilmu Komputer (JPTIIK) Universitas Brawijaya, 2(5), 2548-2964. Retrieved from http://j-ptiik.ub.ac.id

[2.] Afriany, J., Sinurat, L. R. B., Julianty, I., \& Nainggolan, E. L. (2018). Penerapan MOORA Untuk Mendukung Efektifitas Keputusan Manajemen Dalam Penentuan Lokasi SPBU. JURIKOM (Jurnal Riset Komputer), 5(2), 161-166. Retrieved from https:/ejurnal.stmikbudidarma.ac.id/index.php/jurikom/article/view/65 5

[3.] Arifin, F.(2013). Kesesuaian Hidroklimat Padi Pandanwangi (Kasus Kabupaten Cianjur). Jurnal. Bogor. Departemen Geofisika Dan Meteorologi Fakultas Matematika Dan Ilmu Pengetahuan Alam Institut Pertanian Bogor.

[4.] Brauers dan Zavadkas (2006). Definisi Metode MOORA (Multi-Objective Optimization by Ratio Analysis). 
Selviani Kusnadi ${ }^{1,}$ Lalan Jaelani ${ }^{2}$, Sistem Pendukung Keputusan Pemilihan Lahan Untuk Tanam Bibit Pandanwangi Dengan Menggunakan Metode Moora Di Dinas Pertanian Perkebunan Pangan Dan Hortikultura Kabupaten Cianjur)l

[5.] Cholifah, W. N., Yulianingsih, \& Sagita, S. M. (2018). Pengujian Black Box Testing pada Aplikasi Action \& Strategy Berbasis Android Dengan Teknologi Phonegap. Jurnal String Vol 3 No.2, 206.

[6.] Connoly, Begg. (2002). Definisi Database.

[7.] Deliyanto, B. Modul Pengenalan Lahan.

[8.] Destarianto, P., \& Prasiwi, S. B. (2019). Desain Sistem Pendukung Keputusan Pemilihan Lahan Untuk Peningkatkan Produktivitas Tanaman Pangan Di Kabupaten Jember. Jurnal Teknologi Informasi Dan Terapan, 4(1), 17-24. https://doi.org/10.25047/jtit.v4i1.16

[9.] Dewanto. (2015). Konsep Sistem Pendukung Keputusan (SPK).

[10.] Dinas Perdagangan dan Industri Kabupaten Cianjur. 2011. Beras Pandan Wangi. Dinas Perdagangan dan Industri Kabupaten Cianjur, Cianjur.

[11.] Dinas Pertanian Kabupaten Cianjur. 2011. Komoditas Unggulan Kabupaten Cianjur. Dinas Pertanian Kabupaten Cianjur, Cianjur.

[12.] Hatta, H. R., Pratama, N. W., \& Khairina, D. M. (2017). Pemilihan Lahan Terbaik untuk Tanaman Kelapa Sawit menggunakan Metode Simple Additive Weighting. Seminar Nasional Inovasi Dan Aplikasi Teknologi Di Industri, 3(1), A14.1-A14.5.

[13.] Hermanto.(2017). Penilaian Kesesuaian Lahan Untuk Tanaman Kedelai Menggunakan Metode Himpunan Fuzzy Dan Ahp. Skripsi. Semarang. Jurusan Teknik Elektro Fakultas Teknik Universitas Negeri Semarang.

[14.] Kamus Besar Bahasa Indonesia (KBBI), Luar Jaringan (Offline), Pusat Bahasa Kementrian Nasional.

[15.] Khairunnisa, \& Wardoyo, R. (2017). Spk Untuk Merekomendasikan Kesesuaian Lahan Pada Komoditas Tanaman Prioritas Dengan Profile Matching Dan Ahp. Jurnal Ilmiah ILMU KOMPUTER Universitas Udayana, from https://ojs.unud.ac.id/index.php/jik/article/downloa d/39764/24160/.

[16.] Mandal, Sarkar (2012). (DSS) Metode MOORA (Multi-Objective Optimization by Ratio Analysis).

[17.] Mardiana SE., M. (2018). Analisis Penyusunan Anggaran Penjualan Crude Palm Oil (CPO) pada PT Sawit Lestari Betung. Jurnal ACSY: Jurnal Accounting Politeknik Sekayu Vol 7 No. 1, 11.

[18.] Martin, F. (2005). UML Distilled Edisi 3. Yogyakarta: Andi.

[19.] Mesran, M., Pardede, S. D. A., Harahap, A., \& Siahaan, A. P. U. (2018). Sistem Pendukung Keputusan Pemilihan Peserta Jaminan Kesehatan Masyarakat (Jamkesmas) Menerapkan Metode MOORA. Jurnal Media Informatika Budidarma, 2(2), 16-22. https://doi.org/10.30865/mib.v2i2.595
[20.] Nofriansayah , D., \& Defit, S. (2017). Multi Criteria Decision Making (MCDM) Pada Sistem Pendukung Keputusan. Yogyakart: Deepublish.

[21.] Nofriansyah, D. (2017). Multi Criteria Decision Making (MCDM) pada Sistem Pendukung Keputusan. Yogyakarta: Deepublish.

[22.] Nugroho, Prasetyo. A.(2018) Sistem Pendukung Pengambilan Keputusan Pemilihan SMA Swasta Dengan Metode Moora (Multi-Objective Optimization by Ratio Analysis).Skripsi. Yogyakarta. Program Teknik Informatika Universitas Sanata Dharma.

[23.] Nurjanah, A., (2011). Sistem Pendukung Keputusan Untuk Penentuan Lokasi Lahan perkebunan sawit Dengan Menggunakan Metodesimple Additive Weighting (Saw) (Studi Kasus :Pt. Perkebunan Nusantara V (Ptpn V). Skripsi.Pekanbaru. Jurusan Teknik Informatika Fakultas Sains Dan Teknologi Universitas Islam Negeri Sultan Syarif Kasimriau Pekanbaru.

[24.] Nurmi, H. (2016). Membangun Website Sistem Informasi Pariwisata. Jurnal Edik Informatika, 1.

[25.] Pandan Wangi Beras Mashur Khas Cianjur. Dinas Pertanian Kabupaten Cianjur, Cianjur.

[26.] Pratiwi, H. (2016). Buku Ajar Sistem Pendukung Keputusan. Yogyakarta: Deepublish.

[27.] Pratami, Intan I, (2018). Sistem Pendukung Keputusan Penentuan Varietas Bawang Merah Pada Lahan Berbatu(Litosol) Menggunakan Metode Saw(Simple Additive Weighting)Di Kab. Enrekang.Skripsi. Makassar : Jurusan Teknik Informatika Fakultas Sains dan Teknologi UIN Alauddin Makassar.

[28.] Pressman, R. S. (2015). Rekayasa Perangkat Lunak. Yogyakarta: Andi.

[29.] Pressman, R. (2010). Software Engineering. In Software Engineering (Newyork: McGraw Hill).

[30.] Putri, Liestiani S.(2019). Perancangan Sistem Pendukung Keputusan Penilaian Kinerja Untuk Penentuan Asisten Laboratorium Terbaik Dengan Metode Topsis Menggunakan Ionic Framework Di Laboratorium Teknik Informatika Universitas Suryakancana Cianjur. Tugas Akhir. Cianjur : Program Studi Teknik Informatika Universitas Suryakancana.

[31.] Raharjo, B. (2015). Belajar Otodidak MySQL. Bandung: Informatika Bandung.

[32.] Rahmatullah, S., Abdurahman, R., Komputer, T., Informasi, S., Process, A. H., \& Gijul, D. G. (2020). Sistem Pendukung Keputusan Penentuan Lahan Kopi Terbaik Dengan Metode Ahp ( Analytic Hierarchy Process ), (1), 1-11.

[33.] Sandy I. Made. (1995). Tanah, Muka Bumi. Indograph Bakti. FMIPA Universitas Indonesia.

[34.] Soares, T. G., \& Dr. Azhari SN, M. T. (2015). Sistem Pendukung Keputusan Untuk Kesesuaian 
Lahan Komoditas Jagung Di Kabupaten Viqueque. Etd Ugm, 547-559.

[35.] Suparman, U. H. (2015). Buku Persyaratan Permohonan Pendaftaran Indikasi Geografis Beras Pandanwangi Cianjur. Cianjur : (MP3C: Masyarakat Pelestari Padi Pandanwangi Cianjur).

[36.] Supriadi, I., \& Hermawan , A. (2018). Semua Bisa Menjadi Programmer CodeIgniter Basic. Jakarta: PT Elex Media Komputindo.

[37.] Supyandi, D., Sukayat, Y., \& Nugraha, A. (2018). Deskripsi Pengembangan Padi Lokal ( Studi Kasus Padi Pandanwangi Cianjur Dinas Pertanian Kabupaten Cianjur).

[38.] Turban, Sharda \& Delen (2011), Decision Support System (Sistem Pendukung Keputusan).
[39.] Wahana Komputer dan Andi. 2006. Seri Panduan Lengkap Menguasai Pemrograman Web dengan PHP5, Yogyakarta:Andi Offset.

[40.]Yunus, A., \& Rohman, A. C. (2018). Sistem Pendukung Keputusan Penentuan Lahan Pertanian, Pertambangan, Dan Perindustrian (Softplet) Dengan Menggunakan Metode Smarter. SMARTICS Journal, 4(1), 5-10. https://doi.org/10.21067/smartics.v4i1.2693 